\title{
Migración y petróleo en Tabasco
}

\author{
José Luis Lezama*
}

En los inicios de la década de los setenta, el estado de Tabasco fue objeto de fuertes inversiones económicas, cuya finalidad era la explotación y comercialización de las reservas petroleras recién descubiertas. Como consecuencia de esto, se presentaron cambios en la distribución y en el crecimiento social de la población en el interior de la entidad.

En el presente trabajo se analizan las características generales de esos cambios, particularmente las que se refieren a la migración. El análisis está basado, fundamentalmente, en la Encuesta sociodemográfica del estado de Tabasco, levantada por el Consejo Nacional de Población y el gobierno de Tabasco en 1980.

En términos generales, puede decirse que los movimientos migratorios más significativos que se produjeron en la entidad en el periodo petrolero fueron los de carácter intramunicipal, y no los provenientes de otras entidades del pais, como parecía. Estos flujos migratorios, que fundamentalmente se originaron en las rancherías (localidades de menos de 2500 habitantes), no son detectados por los censos de población, razón por la cual el censo de 1980 no da cuenta de un fuerte crecimiento social de la población de Tabasco.

En este trabajo se describe también la dirección de los flujos migratorios y las características de sexo e inserción de los migrantes en la estructura ocu pacional.

\section{Presentación}

El análisis que se realiza en este artículo del impacto petrolero en el crecimiento social de la población de Tabasco, así como de las características generales que ha asumido la migración en la entidad, está sustentado en los datos de la Encuesta sociodemográfica del estado de Tabasco realizada en 1980 por el Consejo Nacional de Población y el gobierno del estado.

Uno de los objetivos de la Encuesta fue detectar los cambios ocurridos en Tabasco a partir de la intensificación de la actividad petrolera, fundamentalmente en cuanto al volumen, la intensidad, la orientación y las características generales de la migración a nivel municipal.

Los resultados que a continuación se exponen constituyen un primer acercamiento a nivel general de estas características. Se ha puesto énfasis en el origen y la dirección de los principales vínculos migratorios antes y después de la intensificación de las actividades petroleras de los años setenta. Por otra parte, se ha completado esta información con datos generales sobre el sexo del migrante y su vinculación con los desplazamientos territoriales y, por último, sobre la inserción de los migrantes en la estructura ocupacional.

* Profesor-investigador del Centro de Estudios Demográficos y de Desarrollo Urbano de El Colegio de México. 
En la primera parte del articulo se mencionan algunos antecedentes históricos generales acerca del petróleo en Tabasco con objeto de mostrar, por un lado, la antigüedad de la industria petrolera en la entidad y, por otro, la importancia económica que dicha actividad posee en el plano de la economía local.

En el estudio de la migración propiamente dicha, y con el propósito de establecer diferencias especificas entre los municipios de destino de los migrantes, se los ha dividido en dos categorías: municipios petroleros y municipios no petroleros. Con ello se pretende distinguir algunas particularidades que caracterizan a los migrantes asociados más directamente a la actividad petrolera, de las de aquellos habitantes de municipios en los que no existe o no tiene demasiada importancia dicha actividad.

Hemos considerado como petroleros los siete municipios cuyos migrantes se insertaron en la actividad petrolera en una proporción que va de 3\% en adelante; dichos municipios son Cárdenas, Centro, Comalcalco, Cunduacán, Huimanguillo y Macuspana. Se incluyó también el municipio de Paraíso dentro del grupo de los petroleros por las fuertes inversiones que ha recibido para la construcción del puerto de Dos Bocas, desde donde se realizarán las exportaciones del petróleo producido en la región.

Los municipios no petroleros son aquéllos cuya población migrante se insertó en la actividad petrolera en una proporción inferior a 3\%, o aquellos que no registran migrantes en esta actividad; estos son Balancén, Centla, Emiliano Zapata, Jalapa, Jalpa, Jonuta, Nacajuca, Tacotalpa, Teapa y Tenosique (véanse los mapas 1 y 2 y los cuadros 6 y 7).

Las definiciones sobre población migrante que se utilizan en este trabajo son las siguientes:

Migración municipal. Está constituida por los desplazamientos poblacionales en el interior del estado de Tabasco, independientemente de que se produzcan dentro de los límites municipales o que sean corrientes migratorias de un municipio a otro. Este concepto tiene como objetivo distinguir entre la población que cambió de lugar de residencia dentro de la propia entidad y la que provino de otros estados del país. La migración municipal se compone de la intramunicipal y de la intermunicipal.

Migración intramunicipal. Se refiere a los movimientos migratorios que tienen lugar dentro de los límites territoriales del municipio. En este sentido, la Encuesta sociodemográfica del estado de Tabasco detecta desplazamientos de población en localidades de menos de 2500 habitantes; de 2500 a 5000 habitantes; de 5001 a 15000 habitantes; de 15001 a 100000 habitantes y de más de 100000 habitantes para cada municipio. La migración intramunicipal estaría integrada por los desplazamientos de población de estas localidades hacia las cabeceras municipales.

Migración intermunicipal. Se forma por los vínculos migratorios entre un municipio y otro dentro del estado de Tabasco. Asi, hemos llamado población migrante intermunicipal a aquella que tuvo como origen un 


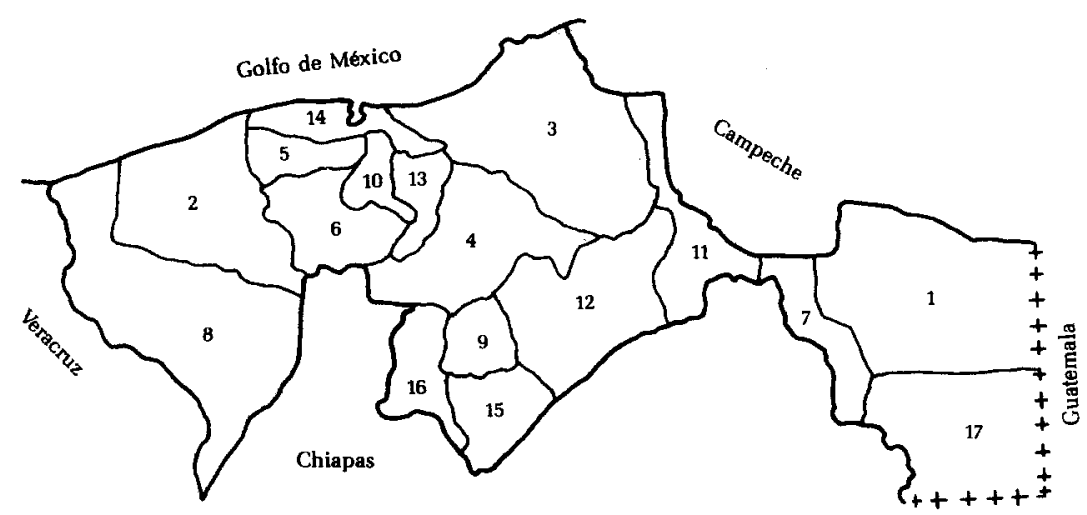
9 Jalapa
10 Jalpa
11 Jonuta
12 Macuspana
13 Nacajuca
14 Paraíso
15 Tacotalpa
16 Teapa
17 Tenosique

municipio distinto del lugar actual de residencia, pero dentro de la entidad.

La distinción entre población migrante intramunicipal e intermunicipal tiene pertinencia puesto que, en las cabeceras municipales de cada municipio, la población migrante puede provenir de otra localidad del propio municipio (intramunicipal), de otro municipio del propio estado de Tabasco (intermunicipal), o de otras entidades del país.

\section{El auge petrolero}

La historia del petróleo en Tabasco tiene ya muchos años. A principios de siglo (véase Taracena, 1974: 12) se dio a conocer un informe de J.W. Walley quien, después de seis años de recorrido por el estado, descubrió la existencia de grandes mantos petrolíferos en la entidad; el informe fue escrito en 1836. Parece que, incluso antes, Manuel Gil y. Saens, el conocido cronista tabasqueño, hablaba ya de la existencia de petróleo en las cercanías del actual municipio de Macuspana. 
No obstante, la explotación del petróleo en tabasco es mucho más reciente; comenzó apenas en los años cincuenta. A finales de ese decenio la entidad ya se había convertido en un importante productor de petróleo y gas natural. En 1973 se anunció el descubrimiento de importantes yacimientosde petróleo en el sureste del país y se inició un intenso proceso de explotación de los hidrocarburos de la zona, que se convertiría pronto en la principal región productora de México.

Las características de la actividad petrolera, en el sentido de sus objetivos económicos suprarregionales, y las tendencias de la economía tabasqueña, que desde años atrás mostraba síntomas de un deterioro de la producción agrícola, pusieron a la entidad en una encrucijada; en ésta se halla en juego el futuro de la evolución económica de Tabasco, ya sea porque la actividad petrolera misma no plantea objetivos de desarrollo en el interior de la entidad, o por el avance de una ganadería extensiva que, como se menciona en Rutsch (1984), practica el método de la ganancia fácil;

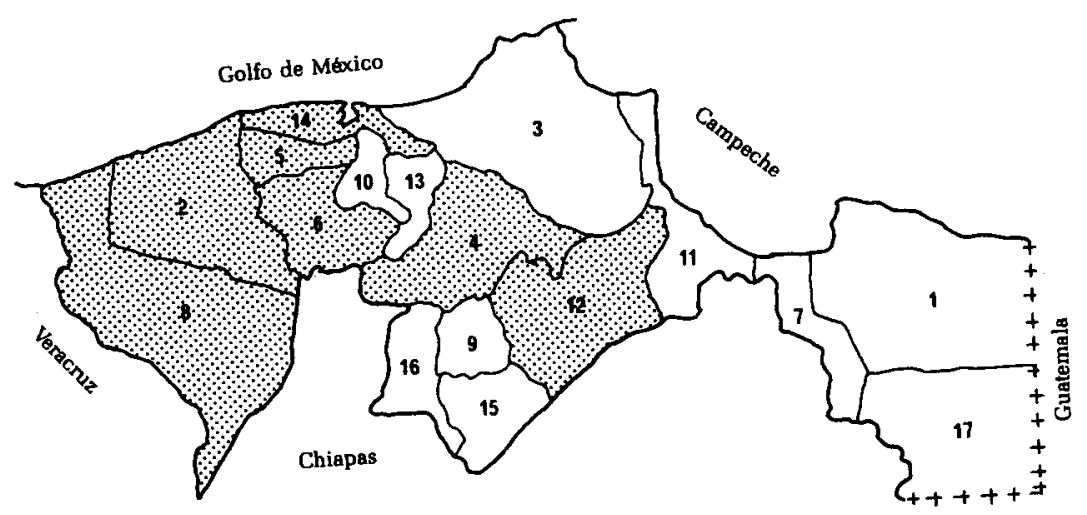

Municipios petroleros

Municipio
1 Balancán
2 Cárdenas
3 Centla
4 Centro
5 Comalcalco
6 Cunduacán
7 Emiliano Zapata
8 Huimanguillo

Municipio

1 Balancán

2 Cárdenas

5 Comalcalco

7 Emiliano Zapata

8 Huimanguillo
9 Jalapa
10 Jalpa
11 Jonuta
12 Macuspana
13 Nacajuca
14 Paraíso
15 Tecotalpa
16 Teapa
17 Tenosique 
contribuyendo al proceso de deterioro del suelo tabasqueño.

Ambos fenómenos (petróleo-ganadería) parecen influir, por una parte, en la reorientación de la economía estatal y, por otra, en las características que en los últimos años han asumido el fenómeno migratorio y la distribución de la población.

En la década de los setenta, el petróleo tuvo una gran importancia en Tabasco. Durante 1976 se realizaron $21 \%$ de las obras que llevó a cabo Pemex en todo el país, concentrando $15.4 \%$ del total de las inversiones. En 1979, la proporción de las obras de Pemex en Tabasco respecto al nacional fue de $27.5 \%$, representando $38.6 \%$ del capital invertido en obras por la empresa en todo el país (CEPAL, 1981: 77). Entre 1970 y 1978 el crecimiento del producto interno bruto del estado parece haber registrado una tasa media anual de $21 \%$. En 1978 , el producto total de la economía tabasqueña en su conjunto se debió en más de tres cuartas partes a la producción petrolera. La participación del sector petrolero en la entidad pasó de $49.5 \%$ en 1970 a $70.4 \%$ en 1978. El sector agropecuario, por su parte, descendió a más de la mitad en la generación del producto estatal en el mismo periodo (CEPAL, 1981: 90).

Para 1979 la producción petrolera en Tabasco ascendió a 400 mil barriles de petróleo crudo y 20 mil millones de metros cúbicos de gas natural. El petróleo extraído del suelo tabasqueño representó para 1980 más de la mitad del total de las exportaciones del país (Lezama y Massolo, 1982: 888).

El dinamismo del sector petrolero también se manifestó en el intenso crecimiento registrado en el número de empleos. En el periodo 1965-1975, la generación de empleos del sector se produjo a una tasa media anual de $4.75 \%$; esta tasa haría que, para 1980, se contara con 7661 trabajadores, cifra que expresa un crecimiento muy acelerado (Rodríguez, 1982: 135). Este singular ritmo de crecimiento del sector petrolero, junto con sus efectos sobre la economía tabasqueña, pueden ser constatados en el incremento del monto promedio de los ingresos de la PEA en el estado. Así, según datos de una encuesta realizada en Villahermosa para 1970 (Jhabvala, 1982: 79), el ingreso promedio mensual de la población, sin considerar el sector agropecuario, la pesca y la caza, fue en el municipio de Centro de 1058.32 pesos, mientras que en el sector petrolero era de 2489.36 pesos; en 1979, el primer grupo tuvo un ingreso promedio de 5539.00 pesos y el petrolero uno de 11046.00 pesos. Esta leve reducción de las diferencias entre uno y otro grupo, la atribuye Jhabvala al efecto multiplicador de la inversión petrolera sobre el resto de los sectores de la economía de la entidad.

Por otra parte, el desplazamiento de las inversiones hacia la zona petrolera de Tabasco ha ido en constante aumento y se ha caracterizado por su carácter selectivo. Esto se manifiesta en la alta concentración de la inversión federal en la industria petrolera de la entidad. Así, puede observárse que entre 1959 y 1963, del total de la inversión pública federal en 
el estado, $77.6 \%$ se destinó al petróleo y sólo $22.4 \%$ a los otros sectores. En el periodo 1971-1976 los recursos destinados al petróleo representaron $72 \%$, mientras que $28 \%$ se canalizaba al resto de los sectores (Lezama y Massolo, 1982).

En términos absolutos, el estado de Tabasco recibió en 1973 una inversión pública federal de 588.4 millones de pesos; para 1979 la inversión federal subió a 17302.7 millones. La derrama económica de Pemex en el estado de Tabasco fue para 1976 de 10961 millones de pesos; en 1979 la cifra se elevó a 69674 millones (Baños, 1984).

Paralelamente a estos hechos y como resultado del incremento de la actividad petrolera que se viene comentando, los ingresos por concepto de los impuestos y participación de Pemex pagados al estado de Tabasco, han ido en constante aumento. En 1973, Pemex aportaba a la entidad 1.5 millones de pesos, 14 millones en 1974, 150 millones en 1975 y más de 650 millones en 1977 (Lezama y Massolo, 1982: 885).

Esta información nos permite detectar, en parte, la magnitud de la presencia de Pemex en la entidad; no obstante, el impacto de la actividad petrolera en el estado no necesariamente se refleja con la misma importancia en los distintos municipios que integran la zona petrolera y en los otros municipios que conforman el estado.

Por otra parte, es cierto que la actividad petrolera ha incidido sobre la intensidad y la orientación de los flujos migratorios, pero también es cierto que el deterioro del agro tabasqueño y el proceso de expulsión de población que parece haber generado, no puede ser atribuido de manera unilateral a la actividad petrolera, ya que este fenómeno, como se ha mencionado, venía ocurriendo desde tiempo atrás en Tabasco.

\section{Migración y petróleo}

El contexto general en el que se insertan las actividades petroleras, sobre todo con la intensidad que tomaron en los años setenta, es el de una entidad que muestra en el sector agropecuario una tendencia creciente al predominio de la ganadería sobre las actividades agrícolas. Este predominio, acompañado de bajas tasas de crecimiento demográfico en general y de bajas tasas de crecimiento de la PEA agropecuaria en particular (sobre todo en las zonas expulsoras de población), sugiere la hipótesis de una posible asociación entre la expulsión de población y el avance de la ganadería. No obstante, sólo un análisis profundo que incorpore un mayor número de variables puede contribuir a aclarar las formas específicas en que se vinculan ambos procesos. La presencia de ambos fenómenos parece darse en algunas zonas de la entidad desde antes de la irrupción petrolera, por lo que habría que explorar, en este sentido, las causas que originaban esa situación; en particular habría que estudiar la estructura 
agraria, cuyas transformaciones seguramente determinaban los procesos de expulsión de población que ocurrían en la entidad, y sobre cuya base se asentó o superpuso el proceso migratorio asociado con la actividad petrolera.

Con el incremento de ésta, Tabasco no mostró síntomas precisos de un importante crecimiento social de su población. Por el contrario, la situación migratoria propia de la entidad, según los datos censales de $\mathbf{1 9 8 0}$, tendió más bien a disminuir la capacidad de atracción que poseia la entidad en el periodo censal anterior (1960-1970).

Es claro que esta situación no parece congruente con todas las evidencias empiricas que se han manejado y con una gran cantidad de material elaborado en los últimos años; en general se hacía referencia al inusitado crecimiento de la población tabasqueña, particularmente como resultado de flujos migratorios provenientes del exterior de la entidad.

En este sentido, los datos del X Censo General de Población y Vivienda del estado de Tabasco, permiten aclarar con mayor precisión los incrementos poblacionales que tuvieron lugar en el estado $y$, en particular en la zona petrolera. ${ }^{1}$ Hasta antes del levantamiento censal se manejaron muchas cifras y se pensó que el crecimiento demográfico de Tabasco habia sido de una gran magnitud, como resultado del incremento de las actividades petroleras. Hoy, a la luz de la información censal y de los datos de la Encuesta sociodemográfica del estado de Tabasco, se sabe que el ritmo de crecimiento de la población de la entidad en el periodo 1970-1980 fue inferior al del decenio anterior, y que la migración interna y externa no redundó en un fuerte movimiento migratorio hacia la zona petrolera, como llegó a pensarse, sino que éste asumió un comportamiento distinto, del que nos ocuparemos más adelante.

El ritmo de crecimiento medio anual de la población en Tabasco en la década 1970-1980, según el censo, fue de 3.19\%; la tasa de crecimiento para el pais en su conjunto en ese mismo periodo fue de $3.2 \%$. En el decenio anterior (1960-1970) la tasa de incremento poblacional de Tabasco había sido de $4.6 \%$, en tanto que a nivel nacional esta tasa fue de $3.4 \%$.

Los datos del censo permiten también apreciar algunos de los cambios que han tenido lugar en la situación migratoria de los municipios del estado de Tabasco en la década 1970-1980. En esté sentido, puede notarse que, contrariamente a lo que se esperaba, los municipios de Tabasco y el estado en general no sólo muestran una tendencia a la disminución de la capacidad de atracción que poseían en 1960-1970, sino que también presentan un significativo aumento de las zonas de expulsión de población.

¿Qué ocurre entonces con los supuestos cambios en el crecimiento

\footnotetext{
${ }^{1}$ En el mapa 2 se indica la ubicación geográfica de la zona petrolera de Tabasco y los municipios que la integran. Hemos llamado petroleros a aquellos que forman esta zona, en tanto que nos referimos a los otros municipios de la entidad como no petroleros.
} 
social de la población y cuáles son las características que pudo haber asumido el fenómeno migratorio en relación a la actividad petrolera de los años setenta? A este respecto, la información proveniente de la Encuesta nos permite establecer lo siguiente:

\section{Distancia de los desplazamientos poblacionales. Migración intramunicipal e intermunicipal}

Los movimientos migratorios que caracterizan al estado de Tabasco consisten fundamentalmente en desplazamientos de población de corta distancia. El que las tasas de crecimiento demográfico para los diversos municipios y para el estado en general no den cuenta de incrementos significativos en los montos poblacionales durante la década 1970-1980, no significa que no se pueda hablar de un importante flujo migratorio en el interior del estado y, en particular, en la zona petrolera. ${ }^{2}$ Lo que sucede es que este proceso migratorio se presenta, de manera preponderante, en el interior de los límites municipales; al tratarse de movimientos migratorios de las pequeñas localidades hacia las cabeceras municipales, no fueron detectados por el censo de población. La característica más relevante del movimiento migratorio en la zona petrolera tabasqueña es su carácter intramunicipal; únicamente en dos municipios (Centro y Cunduacán), no ocurre así, pero esto se explicará más adelante.

En el caso de estos municipios, los migrantes de las cohortes más recientes, así como los de las más antiguas, partieron fundamentalmente de otros municipios de la entidad, por lo que la migración intramunicipal no tuvo la misma importancia que en los otros municipios de la zona petrolera. El predominio de la migración intermunicipal sobre la intramunicipal en el caso del municipio de Centro, podría asociarse tanto con la mayor diversidad económica que lo caracteriza, como con los importantes vínculos con el resto del estado que le asegura su situación, ya que en él se halla la sede del gobierno estatal. En el caso de Cunduacán podría deberse a los bajos volúmenes de su migración y a la ausencia de una tradición migratoria importante.

En los municipios no petroleros de la entidad, la migración intramunicipal es menor que en los petroleros. En este sentido, en cuatro de los municipios no petroleros predominó la migración intramunicipal y en los otros seis tuvo mayor importancia la intermunicipal (véase el cuadro 4).

Ahora bien, en el caso de los municipios petroleros, la migración intramunicipal se intensificó entre las cohortes de migrantes contemporáneas al auge petrolero de los años setenta. Así, en la cohorte de migrantes

\footnotetext{
${ }^{2}$ Del total de desplazamientos poblacionales intermunicipales ocurrido en Tabasco en los 10 an̄os anteriores al levantamiento de la Encuesta, la zona petrolera absorbió $74 \%$, lo cual da cuenta de la importancia de las actividades económicas que tienen lugar ahi.
} 
con más de 11 años de antigüedad, solamente en dos municipios prevalecían los movimientos intramunicipales (véanse los cuadros 3a a 3g). Por el contrario, en la cohorte que ya participa del auge petrolero (menos de tres años de antigüedad), en cuatro de los seis municipios del grupo de los petroleros la migración intramunicipal es la más importante. En los 10 municipios no petroleros no parecen ocurrir cambios muy importantes en esta relación entre migración intra e intermunicipal. Así, en la cohorte de más de 11 años de antigüedad, seis municipios poseen mayor migración intramunicipal y, en la de menos de tres años, siete poseen esta misma característica (véase el cuadro 4).

La corta distancia de los desplazamientos poblacionales en el estado de Tabasco no sólo se hace presente en el carácter intramunicipal de los flujos migratorios. Paralelamente ocurre una migración intermunicipal cuyo rasgo más definido es también su corto alcance territorial, puesto que se efectúa, en mayor medida, entre municipios limítrofes. Esta circunstancia es válida tanto para los municipios petroleros como para los no petroleros.

Si se considera a los siete municipios de la zona petrolera como una región, analizándose separadamente sus principales vínculos migratorios con los municipios que los circundan y con los que se hallan alejados de sus límites geográficos, se tienen nuevos elementos para sostener la argumentación que se viene presentando. En este sentido, la zona petrolera estaría integrada por Cárdenas, Centro, Comalcalco, Cunduacán, Huimanguillo, Macuspana y Paraíso; los municipios circunvecinos serían Centla, Jalapa, Jalpa, Jonuta, Nacajuca, Tacotalpa y Teapa; por último, los no circunvecinos a la zona petrolera serían Balancán, Emiliano Zapata y Tenosique, (véanse los mapas 1 y 2). De esta manera se tiene que, del total de los migrantes intermunicipales que arribaron a la zona petrolera en los diez años anteriores al levantamiento de la Encuesta (1980), 88.2\% se originó en los municipios con los que guarda contigüidad geográfica (circunvecinos) y únicamente $4.3 \%$ provino de los más alejados de la entidad (no circunvecinos) (véase el cuadro 1 ).

Dadas estas particularidades, puede afirmarse que la lógica de la corta distancia se impone tanto por la importancia que poseen los movimientos intramunicipales como por la circunstancia de que, aun en la migración intermunicipal, los flujos más significativos provienen de los municipios circunvecinos a la zona petrolera. La contigüidad geográfica es la principal característica de la migración intermunicipal en la zona petrolera, pero también en los municipios no petroleros, en los que las mayores corrientes migratorias de otros municipios provienen de los municipios circunvecinos (véase el cuadro 2).

En síntesis, puede decirse que, en lo referente a la corta distancia de la migración municipal de la zona petrolera de Tabasco, coinciden tres fenómenos: un predominio de los migrantes de los municipios circunveci- 


\section{CUADRO 1}

Migración hacia la zona petrolera de municipios circunvecinos y no circunvecinos

\begin{tabular}{|c|c|c|c|}
\hline \multirow{2}{*}{$\begin{array}{l}\text { Antigüedad en } \\
\text { la residencia } \\
\text { actual }\end{array}$} & \multicolumn{2}{|c|}{ Procedencia } & \multirow{2}{*}{$\begin{array}{c}\% \text { del total de lo } \\
\text { migración inter- } \\
\text { municipal que } \\
\text { llegó a la zona } \\
\text { petrolera }\end{array}$} \\
\hline & $\begin{array}{c}\text { Circunvecinos* } \\
(\%)\end{array}$ & $\begin{array}{c}\text { No circunvecinos }{ }^{\star *} \\
(\%)\end{array}$ & \\
\hline $\begin{array}{l}\text { De } 6 \text { a } 10 \text { años } \\
\text { De } 1 \text { a } 5 \text { años } \\
\text { menos de } 1 \text { año } \\
\text { TOTAL }\end{array}$ & $\begin{array}{l}94.7 \\
81.3 \\
87.0 \\
88.2\end{array}$ & $\begin{array}{r}5.3 \\
18.7 \\
13.0 \\
11.8\end{array}$ & $\begin{array}{l}85.2 \\
67.8 \\
66.4 \\
74.0\end{array}$ \\
\hline
\end{tabular}

Fuente: Encuesta sociodemografica del estado de Tabasco, Conapo-gobierno del estado de Tabasco.

* Centla, Jalapa, Jalpa, Jonuta, Nacajuca, Tacotalpa, Teapa.

** Balancán, Emiliano Zapata, Tenosique.

nos sobre los no circunvecinos; una alta concentración de la población migrante por la zona petrolera, y una mayor importancia de la migración intramunicipal que de la intermunicipal.

Pero además, el que también en el resto de Tabasco la migración entre municipios circunvecinos sea la más significativa, aun cuando no en todos se presenten con mayor peso los movimientos intramunicipales, permite caracterizar, en términos generales, a la migración de la entidad como desplazamientos poblacionales de corta distancia en los que predominan, en la mayor parte de la zona petrolera y del estado, los movimientos de población de las pequeñas localidades hacia las cabeceras municipales.

\section{CUADRO 2}

Migrantes intermunicipales de hasta 10 años de antigủedad de los municipios no petroleros procedentes de los municipios circunvecinos

\begin{tabular}{|c|c|}
\hline $\begin{array}{lll}\text { Destino } & \text { Procedencia } \\
\end{array}$ & $\begin{array}{c}\text { Municipios circunvecinos } \\
\text { (\%) }\end{array}$ \\
\hline $\begin{array}{l}\text { Balancán } \\
\text { Centla } \\
\text { Emiliano Zapata } \\
\text { Jalapa } \\
\text { Jalpa } \\
\text { Jonuta } \\
\text { Nacajuca } \\
\text { Tacotalpa } \\
\text { Teapa } \\
\text { Tenosique }\end{array}$ & $\begin{array}{r}51.8 \\
77.2 \\
71.1 \\
94.7 \\
78.8 \\
100.0 \\
44.7 \\
100.0 \\
60.0 \\
51.0\end{array}$ \\
\hline
\end{tabular}




\section{Migración por sexo}

Respecto a la migración por sexo pueden extraerse dos tipos de conclusiones generales: una tiene que ver con el sexo de los migrantes municipales y otra vincula el sexo con la distancia de los desplazamientos en términos de su origen intramunicipal o intermunicipal.

En el primer caso se observa que, en la mayor parte de los municipios petroleros, en el periodo más cercano al auge de los años setenta (cohorte de menos de tres años de antigüedad), la migración femenina supera a la masculina; esto ocurre tanto en los movimientos intramunicipales como en los intermunicipales. En aquellos municipios petroleros en los cuales no predomina la migración femenina, ésta participa con porcentajes significativos en la migración municipal total. Así, por ejemplo, tomando como referente a la cohorte de menos de tres años de antigüedad, en el municipio de Cárdenas $\mathbf{3 7 . 3 0 \%}$ de los migrantes municipales eran mujeres. En el municipio de Centro la migración femenina de esta cohorte constituyó $\mathbf{5 8 . 3 8 \%}$. En Comalcalco, las mujeres migrantes fueron $\mathbf{5 0 . 5 0 \%}$ del total. En Cunduacán la migración femenina de la cohorte de menos de tres años de antigüedad contribuyó con $62.60 \%$. En el municipio de Huimanguillo las mujeres representaron $\mathbf{4 7 . 8 0 \% ~ d e l ~ t o t a l ~ d e ~ l a ~ m i g r a c i o ́ n ~}$ municipal. En Macuspana la proporción de mujeres migrantes de esta cohorte fue aún mayor: $70.80 \%$. Finalmente, en Paraíso, del total de la migración municipal contemporánea al auge petrolero, $86.40 \%$ fueron mujeres (véase el cuadro 5).

Al contrario de lo que ocurre en los municipios petroleros, en los no petroleros existe un notorio predominio de los migrantes hombres sobre las mujeres en el grupo de menos de tres años de antigüedad.

En el caso de los migrantes que arribaron a los municipios petroleros antes del auge de los años setenta (11 años y más de antigüedad), se tiene que, en la mayor parte de ellos (Cárdenas, Cunduacán, Huimanguillo, Macuspana) fue más alta la migración municipal de sexo masculino. Por el contrario, en los municipios no petroleros, los migrantes con 11 años y más de antigüedad eran en su gran mayoría mujeres (véase el cuadro 5).

Lo anterior hace suponer, por una parte, que se está ante una migración de carácter familiar, en donde los migrantes hombres se trasladan a los lugares de destino con sus mujeres e hijos y, por otra parte, que las actividades petroleras pudieran haber dado lugar, aun de manera indirecta, a una mayor absorción de la fuerza de trabajo femenina, ya sea en las actividades en donde tradicionalmente se ha insertado esta parte de la población migrante (el trabajo doméstico y el comercio ambulante) o en algunas ramas del sector terciario (las labores administrativas) que la diversificación económica de la industria petrolera pudiera haber abierto.

En la mayoría de los municipios no petroleros los migrantes más recientes (menos de tres años de antigüedad) eran preferentemente hombres 
y los más antiguos (11 y más años) eran en su mayoría mujeres. Los datos muestran, entonces, que en los municipios no petroleros ocurre lo contrario que en los petroleros, en lo que se refiere a los migrantes por sexo con mayor o menor cercanía al auge petrolero. Podría deducirse que estos municipios reproducen la situación migratoria prevaleciente en la entidad antes del auge petrolero. De aquí se desprende que el aumento de la migración femenina de los años setenta pueda ser atribuido al incremento de las actividades petroleras.

En lo que se refiere a la migración por sexo según la distancia de sus desplazamientos, a partir de la información de la Encuesta se pueden enunciar algunas regularidades que caracterizan a la migración en los municipios petroleros. Entre éstos pueden distinguirse tres subgrupos atendiendo a los comportamientos más o menos similares en cuanto al origen de los migrantes según sexo; los subgrupos serían: I. Cárdenas, Comalcalco, Huimanguillo y Macuspana; II. Centro y Cunduacán; III. Paraíso.

El primer subgrupo se caracteriza, en términos generales, por una migración de corta distancia en la cohorte de migrantes más reciente (menos de tres años de antigüedad) que es la que se halla más directamente vinculada a la actividad petrolera. Sin embargo, la proporción de mujeres cuyo cambio de residencia fue hacia una localidad del mismo municipio (migración intramunicipal), fue casi siempre mayor que la de los hombres: 90.14\% en Cárdenas, contra $73.43 \%$ de hombres; $68.52 \%$ en Comalcalco contra $47.60 \%$ de hombres; $70.46 \%$ en Huimanguillo contra $59.46 \%$ de hombres; por último, en Macuspana las mujeres representaron $58.54 \%$, pero los hombres migrantes intramunicipales constituyeron el $100 \%$ (véanse los cuadros 3a, 3c, 3e y $3 f$ ).

En el caso de la cohorte de 11 años y más, la migración intramunicipal tuvo menor peso tanto para los hombres como para las mujeres. En el caso de los hombres, en el municipio de Cárdenas $28.4 \%$ de la migración fue de origen intramunicipal y $71.06 \%$ se originó en otros municipios. En cambio, aun cuando la proporción de origen intramunicipal de las mujeres fue algo mayor $(41.54 \%)$, de todas maneras fue superada por la de origen intermunicipal, que representó el restante $58.46 \%$. En Comalcalco, tanto para hombres como para mujeres predominó la migración intramunicipal (74.77\% y $65.13 \%$, respectivamente); no obstante, las mujeres provinieron más que los hombres de la migración intermunicipal, pues tuvieron como punto de origen otros municipios en $34.87 \%$, por $25.23 \%$ de éstos. En el municipio de Huimanguillo predominó para ambos sexos la migración intermunicipal, en una proporción similar (alrededor de 60\%), sobre la intramunicipal, que se ubicó cerca de $39 \%$. En el caso de Macuspana, la migración intramunicipal fue la más significativa para hombres y mujeres; las mujeres migrantes de origen intramunicipal fueron $54.23 \%$ y los hombres $55.92 \%$. En este subgrupo de municipios y en lo referente a la cohorte de 11 años y más de antigüedad, se presenta como constante que, 


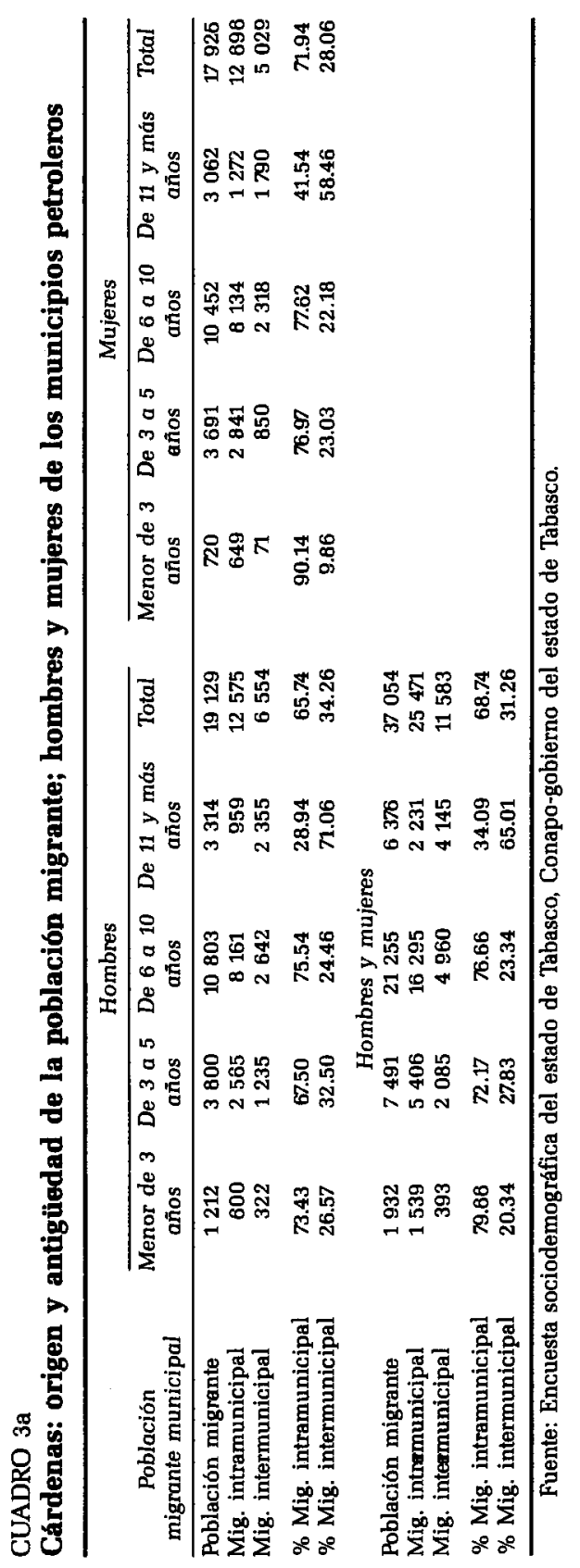



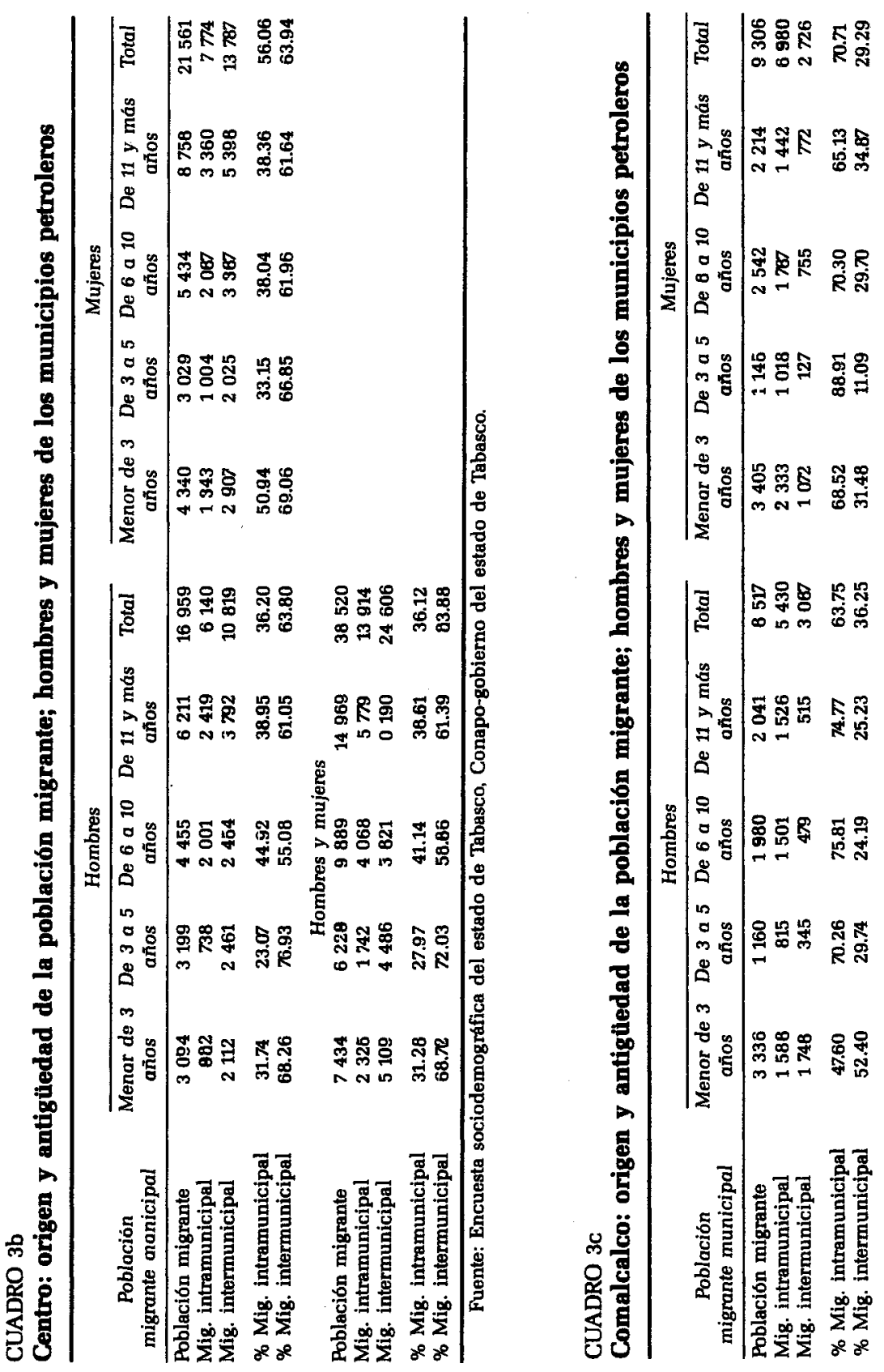
MIGRACIÓN Y PETRÓLEO EN TABASCO
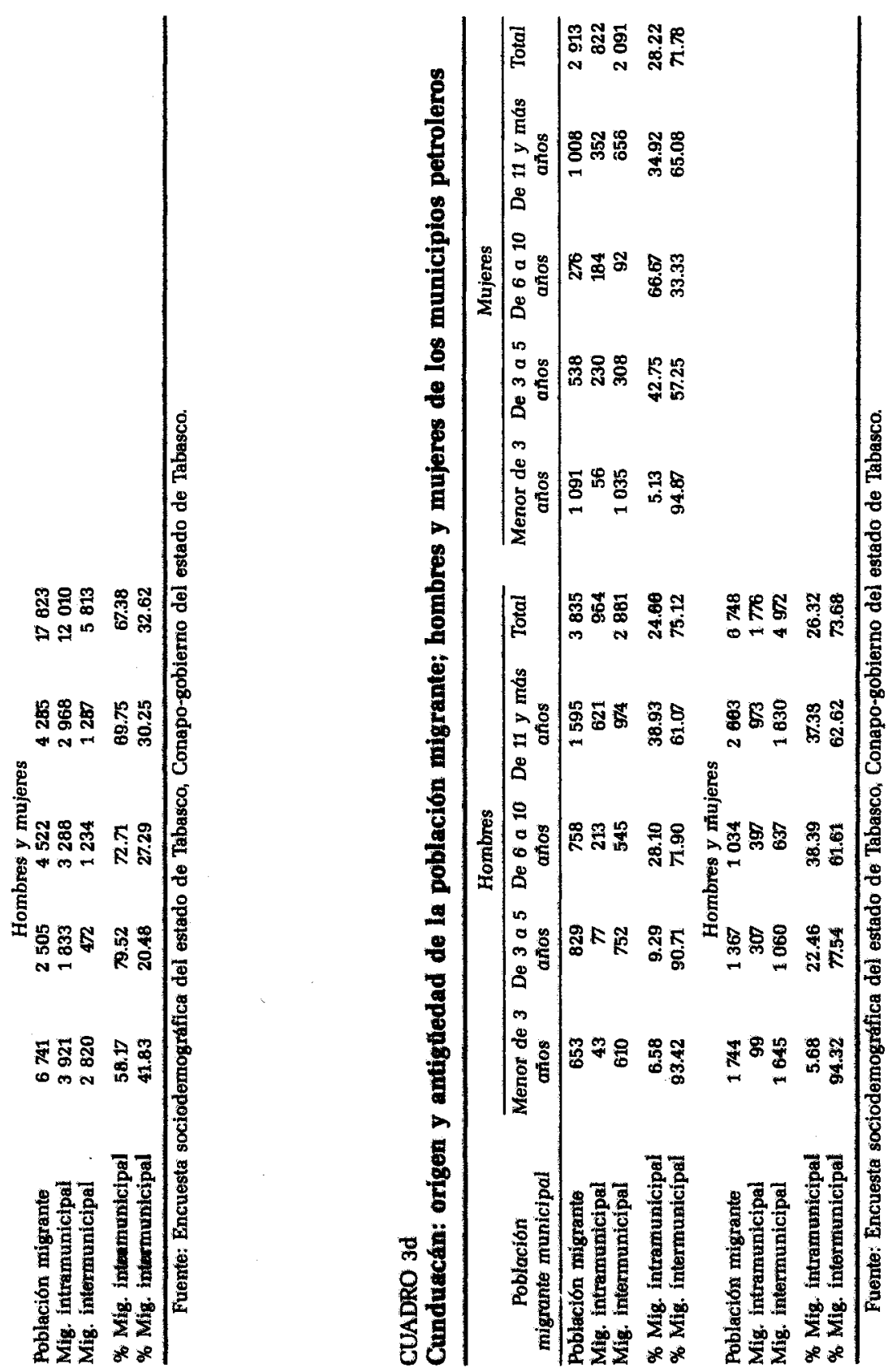

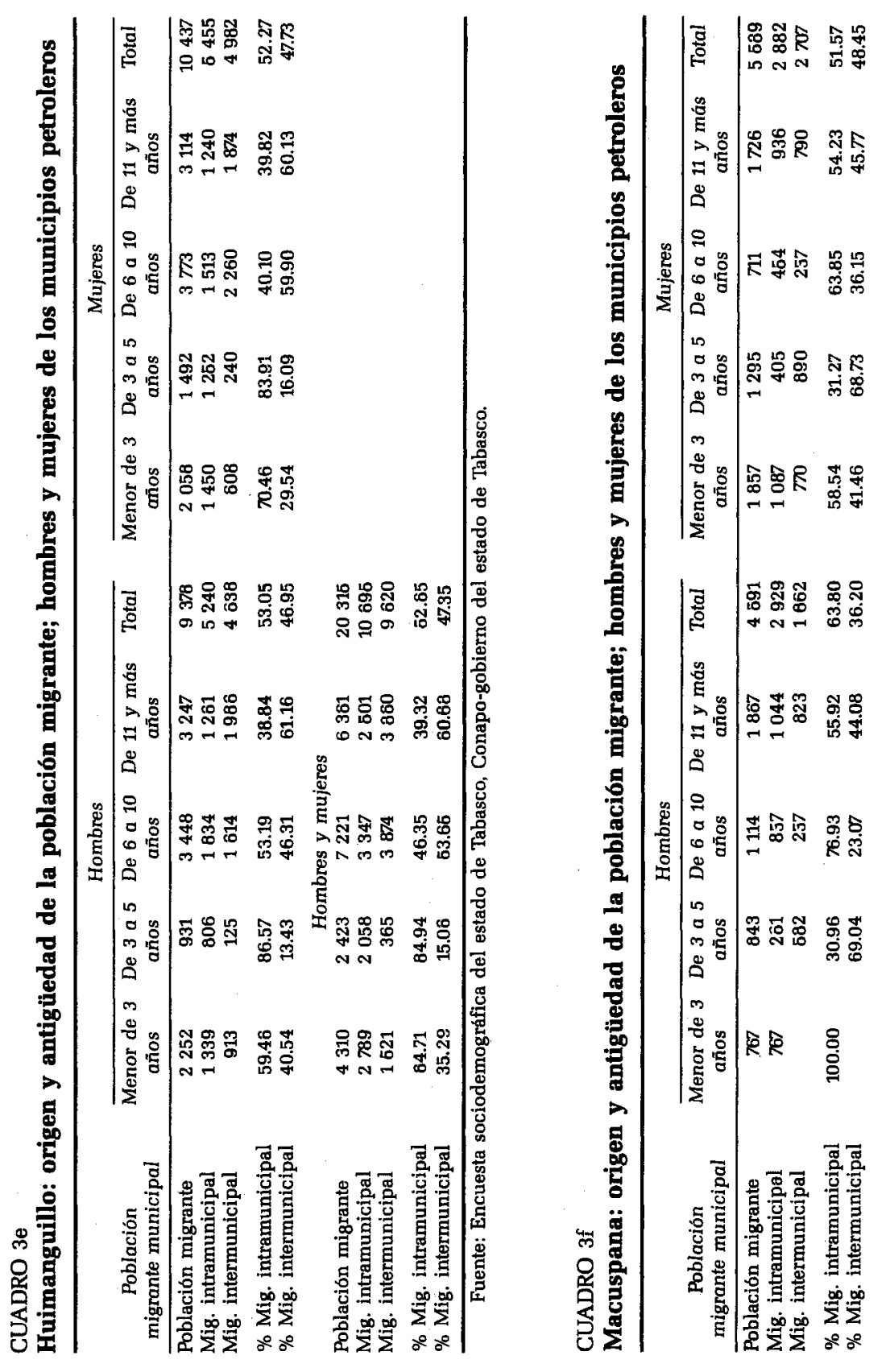
MIGRACIÓN Y PETRÓLEO EN TABASCO
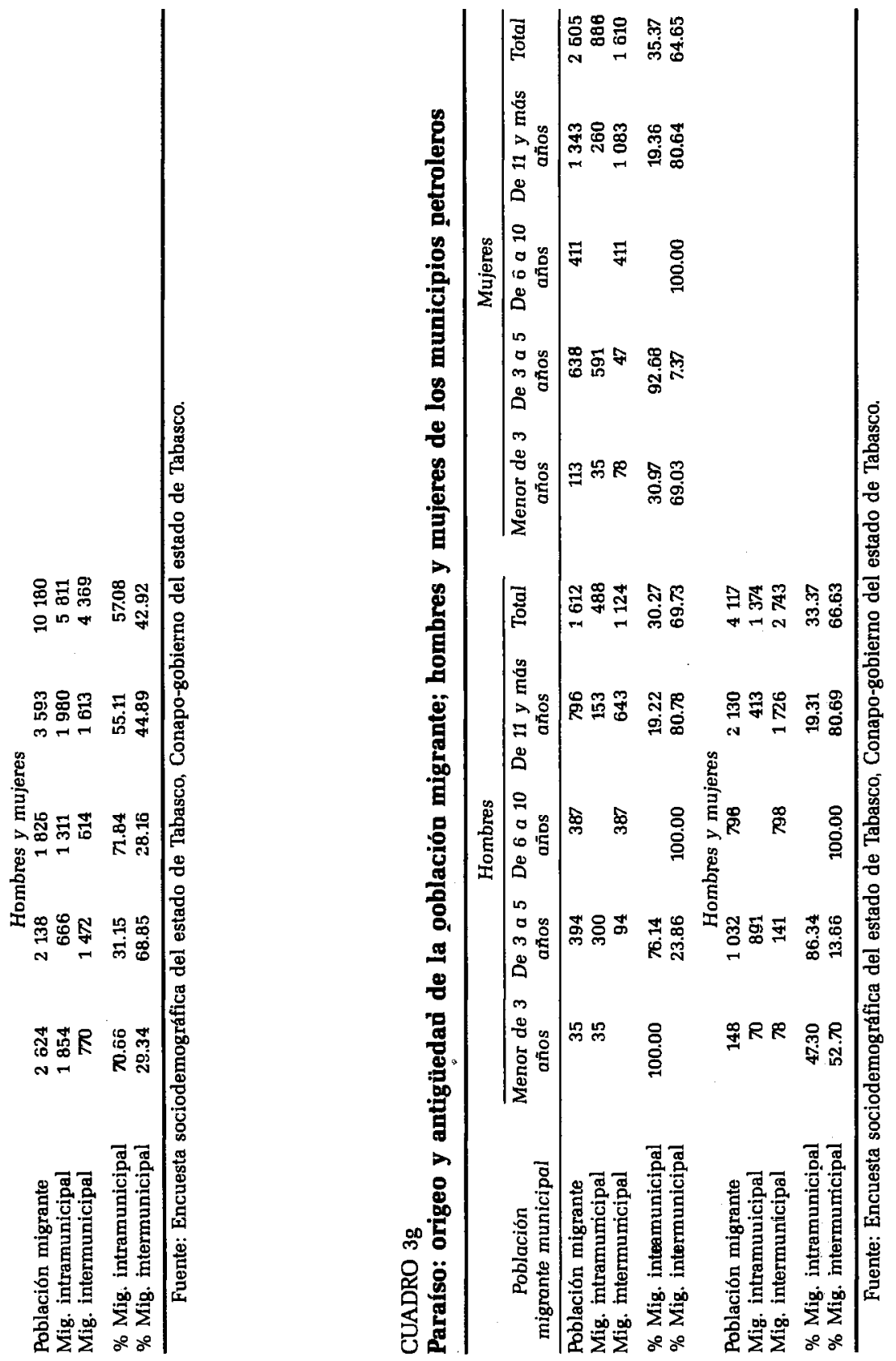


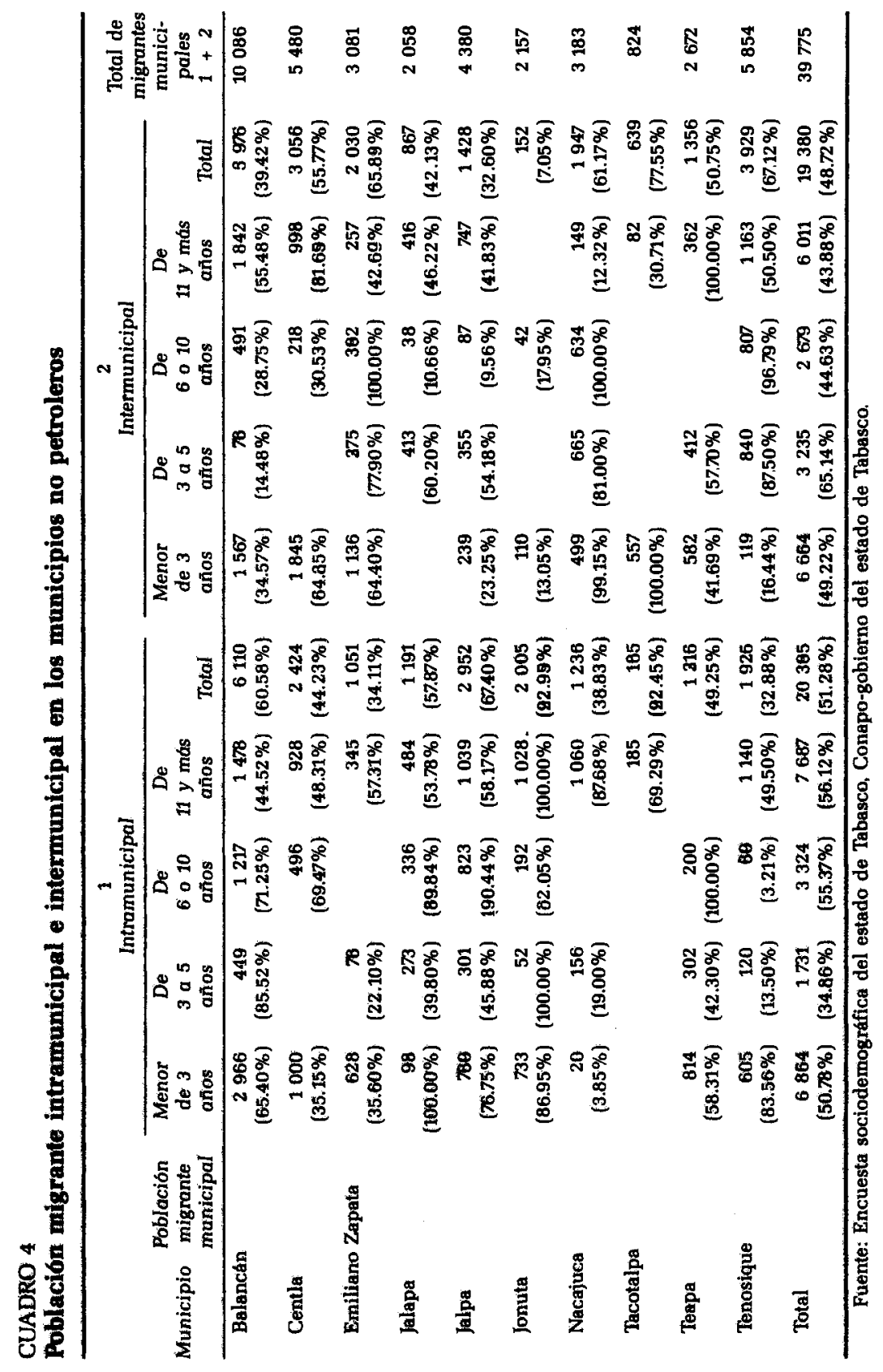


aun cuando en dos municipios predomina la migración intramunicipal para hombres y mujeres y en los otros dos la intermunicipal, las mujeres que tenían como origen otro municipio de la entidad eran proporcionalmente mayoritarias que los hombres.

El segundo subgrupo, es decir los municipios de Centro y Cunduacán, presentó algunas características distintas. En este caso, la proporción de migrantes hombres y mujeres del grupo de menos de tres años de antigüedad provino en una proporción considerablemente menor de la migración intramunicipal. En el municipio de Centro, $31.74 \%$ de los hombres eran migrantes intramunicipales, en tanto que las mujeres migrantes del interior del mismo municipio fueron $30.94 \%$. En Cunduacán, del total de migrantes de sexo masculino de la cohorte de menos de tres años de antigüedad únicamente $6.58 \%$ fue resultado de la migración intramunicipal; las mujeres migrantes del interior del municipio de Cunduacán sólo representaron $\mathbf{5 . 1 3} \%$ de la migración femenina total (véanse los cuadros $3 \mathrm{~b}$ y 3d).

Por el contrario, tanto para los hombres como para las mujeres se observa que, en estos dos municipios, predominó la migración intermunicipal en la cohorte de menos de tres años de antigüedad. Así, por ejemplo, para Centro, 68.26\% de su migración masculina originada en el interior del estado era resultado de la intermunicipal; por otra parte, la migración femenina intermunicipal constituyó $69.06 \%$. En Cunduacán, la migración intermunicipal fue proporcionalmente mayor para las mujeres, con $94.87 \%$. En ambos casos, la migración femenina intermunicipal superó ligeramente a la masculina.

El grupo de migrantes de 11 y más años de antigüedad estuvo también, en mayor medida, representado por la migración intermunicipal que por la intramunicipal; esto ocurrió tanto para los hombres como para las mujeres en los dos municipios de este subgrupo. En Centro, los migrantes de 11 años y más de sexo masculino eran producto de la migración intramunicipal en $38.95 \%$ y las mujeres lo fueron en $38.36 \%$; En Cunduacán, $38.93 \%$ de los migrantes hombres fueron originarios del propio municipio y $34.92 \%$ de las mujeres también provino de la migración intramunicipal. En cambio, la migración intermunicipal siguió teniendo un peso mayor, aunque no tanto como el que alcanzó en la cohorte de menos de tres años de antigüedad. En Centro, la migración masculina intermunicipal del grupo de 11 años y más fue de $61.05 \%$ y la femenina de $61.64 \%$. En Cunduacán, los migrantes intermunicipales hombres constituyeron $93.42 \%$ y las mujeres 65.08 por ciento.

Las pautas seguidas por los municipios de Centro y Cunduacán en lo que se refiere a la alta proporción de migración femenina que han recibido quizá tiene que ver, sobre todo en el caso del primero, con la gran capacidad de su estructura productiva para absorber la fuerza de trabajo femenina. Este hecho vendría a ser acentuado por el incremento de las 
actividades petroleras, pero de ninguna manera sería su consecuencia exclusiva. Además, la diversidad económica del municipio de Centro, en particular en el contexto de la actividad petrolera, puede también explicar el incremento de la migración intermunicipal, tanto para hombres como para mujeres, en el periodo de mayor cercanía al auge petrolero (cohorte de menos de tres años de antigüedad).

Por último, el tercer subgrupo lo integraría el municipio de Paraíso. En este caso no existe una regularidad en su pauta migratoria, por ser un municipio de migración reciente y con una baja corriente migratoria. Su población migrante masculina de menos de tres años de antigüedad, por ejemplo, fue resultado de la migración intramunicipal en su totalidad; en cambio, las mujeres provinieron en $69.03 \%$ de otros municipios. En el grupo de 11 y más años de antigüedad la proporción de migrantes intramunicipales para hombres y mujeres fue mucho menor: 19.22 y 19.36 por ciento, respectivamente. Por el contrario, en la misma cohorte, la migración intermunicipal tuvo una importancia mucho mayor tanto para los hombres como para las mujeres: $80.78 \%$ de los desplazamientos poblacionales de sexo masculino que arribaron a Paraíso fueron de origen intermunicipal, en tanto que las mujeres, bajo esta situación, constituyeron $80.64 \%$ (véase el cuadro $3 \mathrm{~g}$ ).

Finalmente, puede decirse que con el incremento de la actividad petrolera en los años setenta, se presenta un predominio de la migración intramunicipal sobre la intermunicipal en varios de los municipios de la zona petrolera; además, este predominio se hace más patente para la migración femenina. Cuando la migración intermunicipal predomina, tanto para hombres como para mujeres (como puede constatarse para Centro), no se debe sólo a la actividad petrolera, puesto que la migración intermunicipal aparece con mayor peso tanto en las cohortes que ya participan del auge petrolero como en las más antiguas, para las cuales el petróleo no tenía la importancia que adquirió posteriormente.

\section{Inserción de los migrantes en la estructura ocupacional}

Respecto a la inserción de la población migrante en la estructura ocupacional vale la pena mencionar el predominio del sector agropecuario, que siguió siendo el que más capacidad tuvo para absorber la fuerza de trabajo migrante. Esto ocurrió tanto para los municipios petroleros (a excepción de Centro), como para los no petroleros. Es importante destacar que en cuatro de los siete municipios petroleros, el sector agropecuario absorbió una proporción mayor de fuerza de trabajo migrante en el periodo más cercano al impacto petrolero, que la que absorbió en el periodo anterior. En este sentido, vale la pena reconsiderar la supuesta gran capacidad de atracción de población de la industria petrolera. No obstante, en el caso 
de los municipios petroleros, los migrantes presentan una tendencia a ubicarse en la estructura ocupacional de manera diversificada, en tanto que en los municipios no petroleros, la fuerza de trabajo migrante presenta un patrón de inserción en la estructura ocupacional con una alta tendencia a la concentración, particularmente en los sectores agropecuarios y de servicios (véanse los cuadros 6 y 7).

En los municipios petroleros se puede apreciar que junto con la absorción de población migrante por el sector petrolero, se presenta también una importante absorción de esta población por parte de los sectores de la industria de la construcción y de la transformación; este hecho no se presenta o se presenta con menor intensidad en los municipios no petroleros. Esta circunstancia permite sugerir la hipótesis de una activación de esos sectores como consecuencia de la industria petrolera.

La información proveniente de la Encuesta permite señalar también la existencia de una asociación entre la actividad petrolera y una tendencia a la disminución de la población migrante que se ubica en el sector servicios. Entre menos fuerte es la presencia del sector petrolero en la zona, mayor es la fuerza de trabajo que se inserta en el sector servicios y mayor parece ser la tendencia a la concentración de la inserción de la fuerza de trabajo, tanto en el sector agropecuario como en el de servicios. En Cárdenas y Centro, que son los dos municipios donde el impacto de la actividad petrolera ha sido más intenso, se presenta este fenómeno muy claramente. Así, por ejemplo, en las cohortes de migrantes con mayor cercanía al auge petrolero, aparece esta tendencia a la diversificación de la inserción de la fuerza de trabajo en la estructura ocupacional, paralelamente con una mayor absorción de la fuerza de trabajo migrante por el sector petrolero y una menor proporción de esta misma fuerza de trabajo en el sector servicios. En Comalcalco y Macuspana, donde la presencia de Pemex es anterior al auge de los años setenta, se tiene este mismo fenómeno, pero en tiempos distintos. En estos municipios, particularmente en Macuspana, la actividad petrolera de más intensidad tuvo lugar a fines de los años cincuenta y en la década de los sesenta. En este contexto, las cohortes de migrantes de 11 años y más fueron absorbidas en una mayor proporción por el sector petrolero; este hecho se presentó junto con una menor proporción de fuerza de trabajo migrante ocupada en el sector servicios. Por el contrario, en las cohortes de migrantes con menos antigüedad, es decir, las que llegaron motivadas por el incremento de la actividad petrolera de los años setenta, se presentó una menor capacidad del sector petrolero en la absorción de fuerza de trabajo migrante, mientras que el sector servicios absorbió proporciones más significativas de esta fuerza de trabajo. En el caso de estos municipios, el auge de los años setenta no significó lo que para el resto de la zona petrolera, puesto que ya para esas fechas habían disminuido su producción

En síntesis, puede concluirse que a partir de los datos censales de 


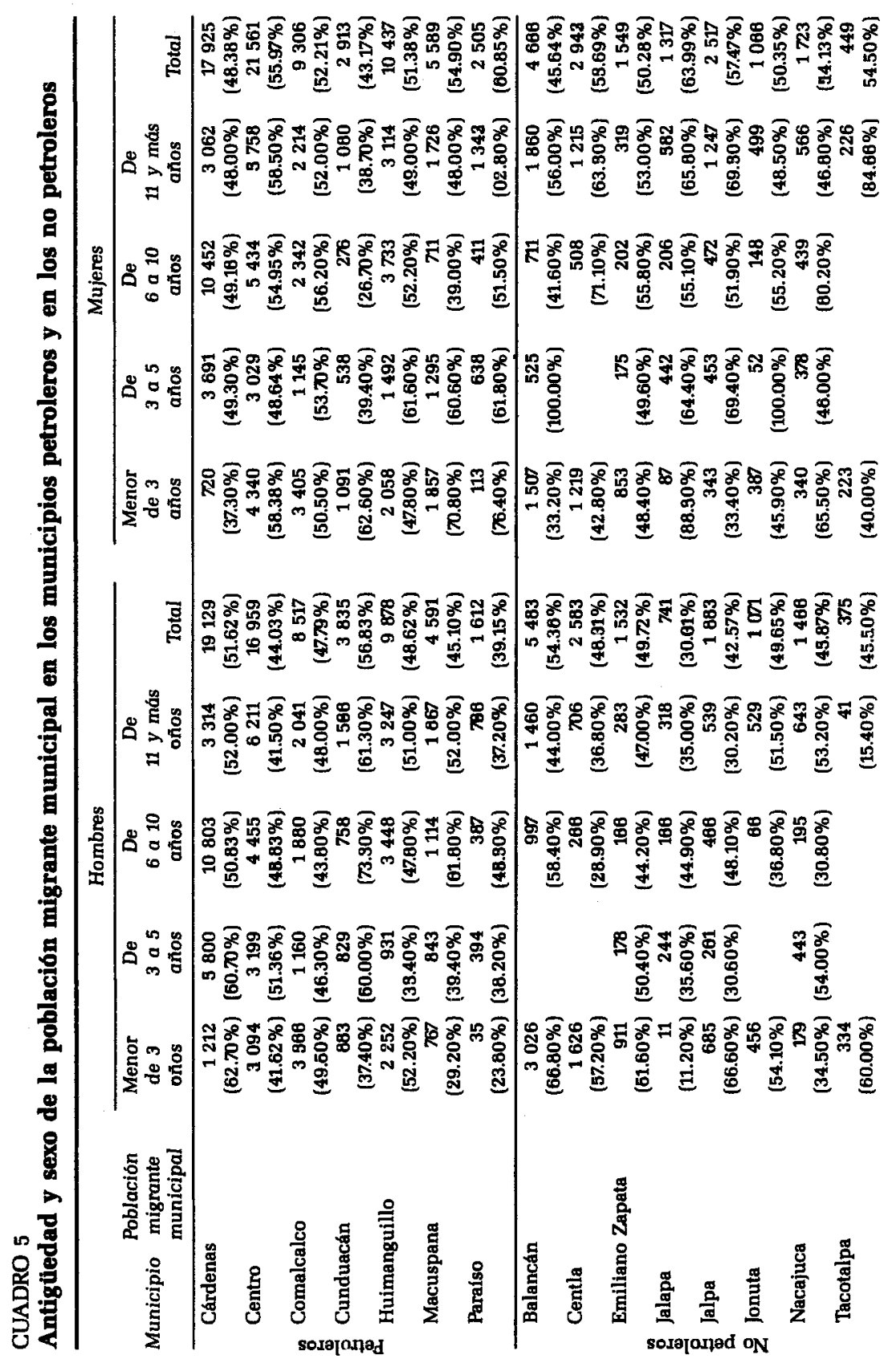



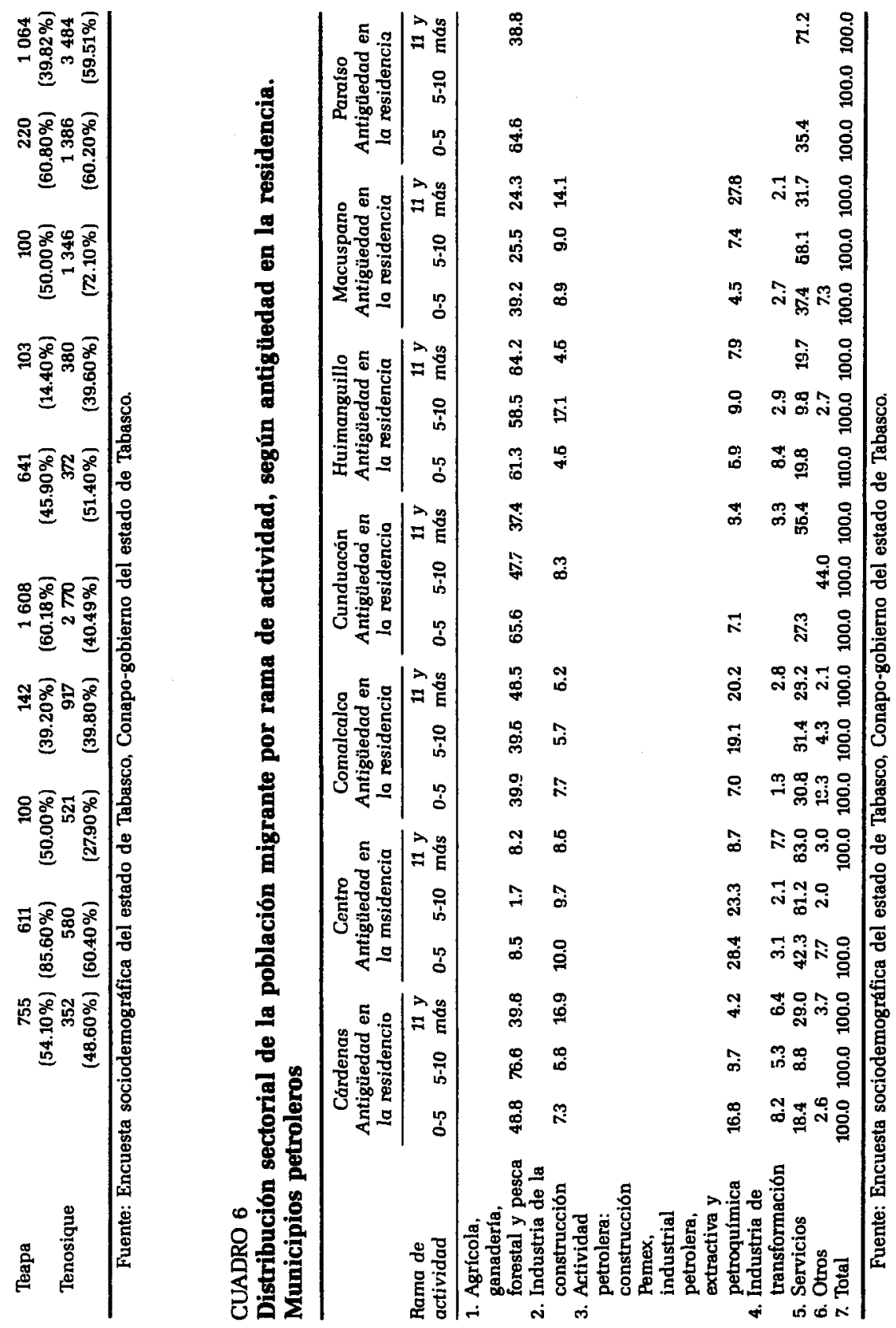
CUADRO 7

Distribución sectorial de la población migrante por rama de actividad, según antigüedad en la residencia. Municipios no petroleros

\begin{tabular}{|c|c|c|c|c|c|c|c|c|c|c|c|c|}
\hline \multirow[b]{2}{*}{ Rama de actividad } & \multicolumn{3}{|c|}{$\begin{array}{c}\text { Balancán } \\
\text { Antigüedad en } \\
\text { ja residencia }\end{array}$} & \multicolumn{3}{|c|}{$\begin{array}{c}\text { Centia } \\
\text { Antigüedad en } \\
\text { la residencia }\end{array}$} & \multicolumn{3}{|c|}{$\begin{array}{c}\text { Emiliano Zapata } \\
\text { Antigüedad en } \\
\text { la residencia }\end{array}$} & \multicolumn{3}{|c|}{$\begin{array}{c}\text { Jalapa } \\
\text { Antigüedad en } \\
\text { la residencia }\end{array}$} \\
\hline & $0-5$ & $5-10$ & $\begin{array}{l}11 \text { y } \\
\text { más }\end{array}$ & $0-5$ & $5-10$ & $\begin{array}{l}11 \text { y } \\
\text { más }\end{array}$ & $0-5$ & $5-10$ & $\begin{array}{l}11 \text { y } \\
\text { más }\end{array}$ & $0-5$ & $5-10$ & $\begin{array}{l}11 \text { y } \\
\text { más }\end{array}$ \\
\hline $\begin{array}{l}\text { 1. Agricultura, ganadería, } \\
\text { forestal y pesca }\end{array}$ & 38.5 & 59.8 & 49.9 & 17.8 & 23.7 & 70.2 & 18.3 & 14.7 & 29.6 & 26.2 & 30.1 & 72.1 \\
\hline $\begin{array}{l}\text { 2. Industria de la construoción } \\
\text { 3. Actividad petrolera: } \\
\text { construcción Pemex, } \\
\text { industrial petrolera } \\
\text { extractiva y petroquímica }\end{array}$ & 17.0 & 32.2 & 24.6 & & 11.6 & . & & 7.9 & 6.2 & 6.6 & & 2.2 \\
\hline 4. Industria de transformación & 10.9 & & & 2.2 & & & & & & & & \\
\hline 5. Servicios & 33.6 & 8.0 & 17.4 & $\pi .2$ & 53.1 & & 81.7 & 65.4 & 64.2 & 67.2 & 69.9 & 25.7 \\
\hline 6. Otros & & & 8.1 & 13.8 & 11.6 & 29.8 & & 12.0 & 3.7 & & & \\
\hline 7. Total & 100.0 & 100.0 & 100.0 & 100.0 & 100.0 & 100.0 & 100.0 & 100.0 & 100.0 & 100.0 & 100.0 & 100.0 \\
\hline
\end{tabular}

1980 y de la Encuesta sociodemográfica de 1980, no se detecta la existencia de un movimiento migratorio intermunicipal y de otras entidades hacia la zona petrolera de Tabasco con la intensidad y las magnitudes con las que se había mencionado anteriormente; antes bien, si nos basáramos exclusivamente en la información censal, por medio de la división del estado en zonas de expulsión y atracción de población, se vería que las zonas de expulsión de población de la entidad aumentaron en el periodo 19701980 y que el estado mismo presentó una dinámica demográfica de menor intensidad que en la década precedente (1960-1970).

Pero la Encuesta sociodemográfica del estado de Tabasco nos muestra que sí se produjeron importantes movimientos migratorios en el periodo petrolero, y que éstos asumieron una forma particular.

Las altas tasas de incremento demográfico que supuestamente estaban asociadas a la demanda de fuerza de trabajo de la actividad petrolera, no aparecen registradas por la información censal. Ello se debe en parte a que los más importantes desplazamientos de población en los municipios de la zona petrolera no son los provenientes de otros municipios o de otros estados; más bien es la propia migración en el interior de cada municipio, particularmente de las rancherías de Tabasco, la que nutre de migrantes a las cabeceras municipales; por tanto, es la migración intramunicipal la que se impone con mayor peso en la zona petrolera en particular y en el resto de los municipios en general.

Por otra parte, la migración intermunicipal que llegó a la zona petrolera, presentó la peculiaridad de la corta distancia, detectándose, funda- 
(continuación)

\begin{tabular}{|c|c|c|c|c|c|c|c|c|c|c|c|c|c|c|c|c|c|}
\hline \multicolumn{3}{|c|}{$\begin{array}{l}\text { Jalpa } \\
\text { Antigüedad en } \\
\text { la residencia }\end{array}$} & \multicolumn{3}{|c|}{$\begin{array}{l}\text { Jonuta } \\
\text { Antigüedad en } \\
\text { la residencia }\end{array}$} & \multicolumn{3}{|c|}{$\begin{array}{c}\text { Nacajuca } \\
\text { Antigüedad en } \\
\text { la residencia }\end{array}$} & \multicolumn{3}{|c|}{$\begin{array}{c}\text { Tacotalpa } \\
\text { Antigüedad en } \\
\text { la residencia }\end{array}$} & \multicolumn{3}{|c|}{$\begin{array}{c}\text { Teapa } \\
\text { Antigüedad en } \\
\text { la residencia }\end{array}$} & \multicolumn{3}{|c|}{$\begin{array}{c}\text { Tenosique } \\
\text { Antigüedad en } \\
\text { Ia residencia }\end{array}$} \\
\hline $0-5$ & $5-10$ & $\begin{array}{l}11 \text { y } \\
\text { más }\end{array}$ & 0.5 & $5-10$ & $\begin{array}{l}11 \text { y } \\
\text { más }\end{array}$ & $0-5$ & $5-10$ & $\begin{array}{l}11 \text { y } \\
\text { más }\end{array}$ & $0-5$ & $5-10$ & $\begin{array}{l}11 \text { y } \\
\text { más }\end{array}$ & $0-5$ & $5-10$ & $\begin{array}{l}11 \text { y } \\
\text { más }\end{array}$ & $0-5$ & $5-10$ & $\begin{array}{l}11 \text { y } \\
\text { más }\end{array}$ \\
\hline \multirow[t]{2}{*}{21.6} & 53.8 & 42.1 & 41.6 & $\begin{array}{l}39.8 \\
60.2\end{array}$ & 93.3 & 52.6 & 27.5 & $\begin{array}{r}84.7 \\
0.7\end{array}$ & 100.0 & & 100.0 & $\begin{array}{l}51.7 \\
12.4\end{array}$ & 100.0 & 77.7 & $\begin{array}{l}15.9 \\
23.9\end{array}$ & 57.2 & $\begin{array}{r}21.2 \\
4.8\end{array}$ \\
\hline & & & 18.6 & & & & & 2.4 & & & & & & & & 9.6 & \\
\hline 78.4 & 46.2 & 57.9 & 39.8 & & 6.7 & 47,4 & 72.5 & 12.4 & & & & 35.9 & & 22.3 & 60.2 & 33.2 & 74.0 \\
\hline
\end{tabular}

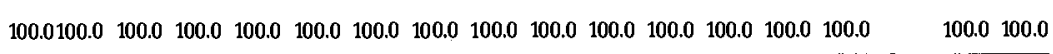

mentalmente, movimientos migratorios desde los municipios circunvecinos a la zona petrolera.

Por eso se afirma en este trabajo que uno de los rasgos esenciales de la migración municipal en Tabasco es la corta distancia de los desplazamientos poblacionales, lo cual se hace patente tanto por el predominio de la migración intramunicipal sobre la intermunicipal, como porque en esta última la contigüidad geográfica aparece como una de sus principales características.

Además, un hecho particular que se presenta en la migración del interior de Tabasco es el predominio, en los municipios que integran la zona petrolera, de la migración femenina sobre la masculina. Otra característica es que en el periodo de mayor proximidad al auge petrolero, se acentúa la migración femenina de origen intramunicipal.

Por último, se advierte también una inserción más diversificada de la fuerza de trabajo migrante en la estructura ocupacional de los municipios petroleros en la cohorte más cercana al petróleo, que en aquella que no participa de la influencia de esta actividad. De igual manera, entre mayor es la presencia del petróleo, parece ser menor la población migrante ocupada en el sector servicios. Por el contrario, la ausencia de la actividad petrolera, ya sea que se analice con las cohortes de 11 años y más de los municipios petroleros o en los municipios no petroleros, se presenta asociada con una alta concentración de los migrantes en el sector agropecuario y en el de servicios. 


\section{Bibliografía}

Baños Ramírez, Othón (1984), Campesinos y petroleros en Tabasco, El Colegio de México (Cuadernos del CEs 31), México.

CEPAL (1981), Algunos efectos del desarrollo petrolero en la evolución económica y social del estado de Tabasco, México.

Jhabvala, Firdaus (1982), "El crecimiento forzado de Tabasco", en Impactos regionales de la política petrolera en México, Ciss, México.

Lezama, José Luis y Alejandra Massolo (1982), "Cambios sociodemográficos y auge petrolero en Tabasco", en Investigación Demográfica en México, 1980, Conecyt, México.

Rodríguez, Rolando (1982), "Estructura de la demanda ocupacional", en Impactos regionales de la política petrolera en México, CIIS, México.

Rutsch, Mechthild (1984), La ganadería capitalista en México, Editorial Línea, México.

Taracena, Alfonso (1974), Historia de la Revolución en Tabasco, Ediciones del gobierno del estado de Tabasco, Villahermosa. 